\title{
Forma y función de los instrumentos líticos del sitio Paso Otero 3 (pdo. de Necochea, pcia. de Buenos Aires, Argentina): un estudio comparativo
}

\author{
LANDINI, C. *, BONOMO, M. ${ }^{* \star}$, LeIPUS, M. ${ }^{* *}$, y MARTinez, G. ${ }^{* \star \star}$
}

RESUMEN

En este trabajo se aborda el análisis tecno-morfológico y funcional de los instrumentos líticos recuperados en el sitio arqueológico Paso Otero 3 (Pcia. de Buenos Aires, Argentina). El material analizado corresponde a un

sitio de matanza y procesamiento primario, producto de las actividades

de grupos cazadores recolectores, datado en $4777 \pm 77$ años C14 A.P. El conjunto recuperado está conformado por material faunístico, en su mayoría a huesos de guanaco, y material lítico consistente en instrumentos con retoque unifacial y desechos de talla.

Los objetivos de este trabajo son comparar los resultados obtenidos del análisis tecno-morfológico de los instrumentos líticos, con aquellos alcanzados a través del análisis funcional de los mismos. Creemos que este tipo de estudio comparativo es

\section{ABSTRACT}

This paper deals with the technomorphological and functional aspects of lithic tools recovered from the Paso Otero 3 site (Buenos Aires Province, Argentine). The site was defined as a kill and primary processing loci based on the characteristics of faunal remains and lithic debris and it was chronologically dated to $4,777 \pm 77$ years $B P$.

The main goal of this paper is to compare the results obtained from two different lines of evidence resulting from techno-morphological and microwear analyses of lithic tools. The results obtained in this comparative analysis show that some of the functions commonly assigned to specific "types" were not performed by these artefacts. Moreover, additional information was

* INCUAPA Fac. Cs. Sociales-UNC, FCN y M-UNLP.

** CONICET, FCN y M-UNLP.

*** CONICET, INCUAPA, Fac. Cs. Sociales-UNC. 
importante pues arroja nueva información que complementa a la clásica aproximación tecnomorfológica de los instrumentos. En suma, este enfoque provee datos que aportan al entendimiento de la explotación del ambiente, tanto de las materias primas líticas como de los recursos de subsistencia y por lo tanto generan información adicional que ayuda a comprender aspectos de la funcionalidad del sitio.

PALABRAS CLAVES

Región Pampeana, cazadoresrecolectores, material litico, análisis tecno-morfológico, análisis funcional. obtained from the microwear analysis which indicates the raw materials that were modified by using this tool assemblage.

This comparative approach provides new insights into the understanding of both the exploitation of different resources and the activities carried out in these specific activity sites generated by hunter-gatherer societies who inhabited the Pampean Region during the middle Holocene.

\section{KEY-WORDS}

Pampean Region, hunter-gatherers, lithic material, techno-morphological analysis, functional analysis.

\section{INTRODUCCIÓN}

La relación entre la morfología y la función de los instrumentos líticos, ha sido sin duda uno de los temas más discutidos desde los comienzos de las investigaciones arqueológicas. Para abordar esta problemática es necesario por un lado analizar aspectos tecno-morfológicos que permitan agrupar los artefactos en categorías tipológicas, inferir técnicas de manufactura, cadenas operativas, etc. Por otro lado aplicar la metodología funcional que brinde información acerca del modo de utilización de los instrumentos líticos y de los materiales que han sido trabajados.

El estudio de los aspectos funcionales de los instrumentos líticos arqueológicos puede realizarse desde diferentes perspectivas. Desde un punto de vista histórico, una de las aproximaciones más aplicada ha sido, sin duda, la analogía formal entre los artefactos líticos que se estudian y otros cuya función es conocida a través de los enfoques actualísticos (etnográficos, etnoarqueológicos, experimentales, ver entre otros, Gallagher 1979; Gould 1973; Gould et al. 1971; Hayden y Kamminga 1973). También se ha intentado identificar la función analizando la potencialidad de los artefactos para realizar una actividad o transformar un material concreto, teniendo en cuenta criterios como materia prima, morfología, extensión y ángulo del filo, tipo de retoque, (Franco y Carballo Marina 1993; Hayden 1979; Hester y Heizer 1973; Hester et. al. 1973; Miller 1979; Nance 1971; Wilmsen 1968a y b; Wilmsen y Roberts 1970 , entre otros). 
El problema principal de estas aproximaciones reside en que sólo permiten plantear hipótesis de uso que, sin embargo deben ser contrastadas. En este sentido, los rastros microscópicos de los instrumentos líticos constituyen uno de los mejores elementos de análisis para inferir los diversos tipos de procesos (utilización, alteraciones postdepositacionales, etc.) a los que han estado sometidos desde su confección. En efecto, el análisis funcional de base microscópica es el único método, hasta el presente, mediante el cual se llega a la identificación de los diferentes tipos de materiales y sustancias trabajados, como así también de los modos de uso específicos de los artefactos líticos. Desde una óptica más amplia, su aplicación permite definir diversas actividades llevadas a cabo por un grupo humano en el pasado, pudiendo relacionarlas con aspectos del aprovechamiento de los recursos del ambiente, principalmente en contextos arqueológicos donde la evidencia de los mismos resulta, en cierta medida, escasa (ct. Mansur 1999; Mansur-Franchomme 1987).

Desde esta perspectiva, el objetivo de este trabajo es establecer el grado de correspondencia entre morfología y función artefactual, es decir, analizar si existe tal correspondencia entre la caracterización tecno-morfológica, la función generalmente asignada a tal construcción y la información derivada de los estudios microscópicos. Para ello se compararon los resultados obtenidos, en forma independiente, a partir del análisis tecno-morfológico con aquellos alcanzados a través del análisis funcional de los instrumentos recuperados en el sitio arqueológico Paso Otero 3.

\section{ANTECEDENTES DEL SITIO}

El sitio Paso Otero 3 está ubicado en la margen izquierda del río Quequén Grande (Pdo. de Necochea, Pcia. de Buenos Aires) a los 58 12 ' $31^{\prime \prime}$ LS y a los 59 06' 35" LO, este curso de agua se encuentra en el área Interserrana Bonaerense de la Región Pampeana, Argentina (Mapa 1). En rasgos generales, se recuperó material faunistico correspondiente en su mayoría a huesos de guanaco y material lítico consistente en instrumentos con retoque unifacial marginal y desechos de talla.

Aunque los análisis estratigráficos están en su fase preliminar, se ha determinado que los sedimentos que contienen el material arqueológico pueden ser asignados a la parte superior de los depósitos fluviales del Miembro Río Salado de la Formación Luján (sensu Fidalgo et al. 1973). Más específicamente, el material arqueológico se encuentra asociado a 


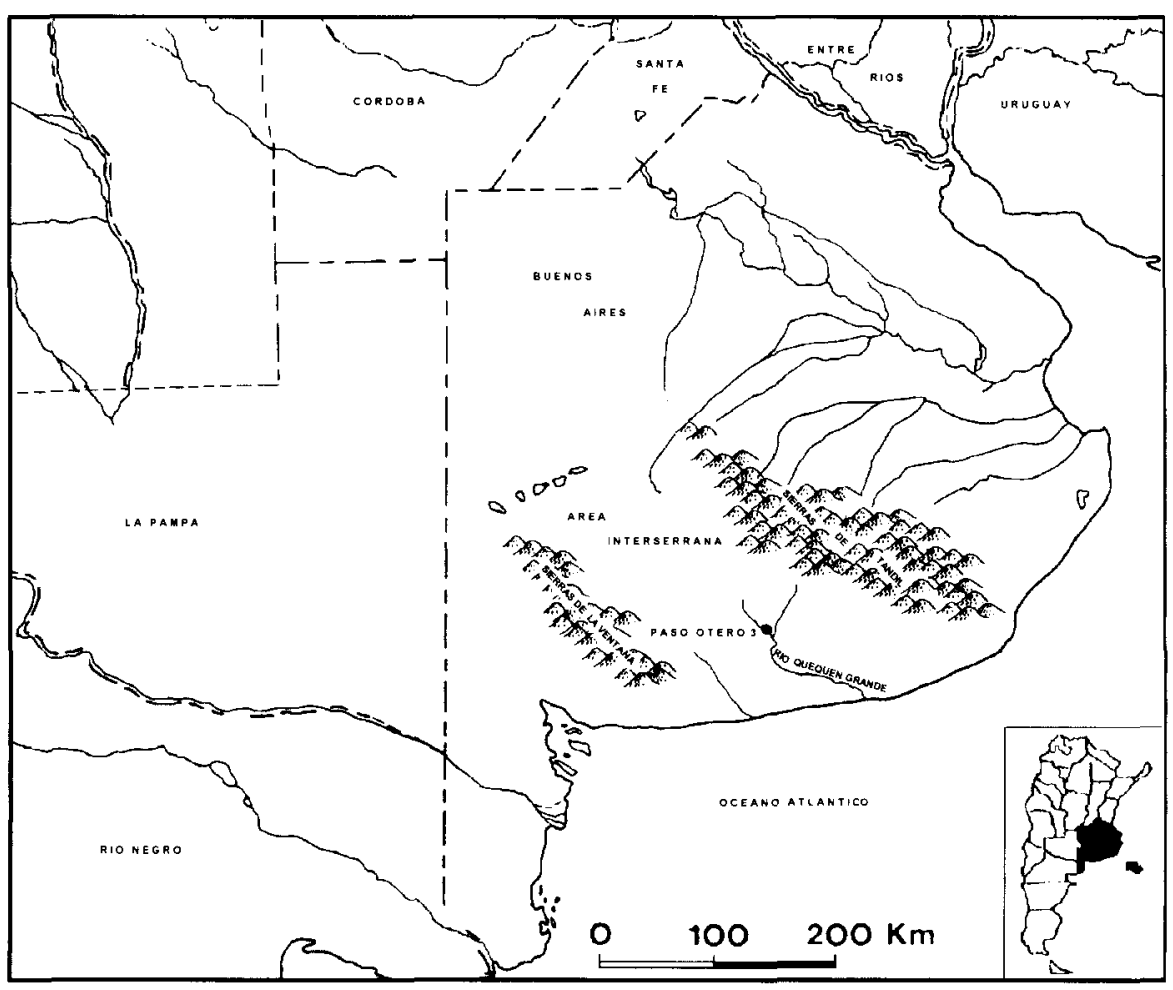

Mapa 1: Ubicación de Paso Otero 3.

una superficie de estabilización del paisaje, un horizonte "A» de suelo enterrado, donde una muestra de materia orgánica fue fechada en $4777 \pm 77$ años C14 A.P. (DRI 3069), que permite atribuir la ocupación al Holoceno medio. (Martínez 1999; ver figura 2 en Martínez et al. 1997-1998:6; Martínez y Gómez e.p.; Martínez et al. e.p.).

A través del análisis de los artefactos líticos recuperados, se registró la presencia de material representativo de las últimas etapas de la producción de instrumentos (Collins 1975; Magne 1989). En base, fundamentalmente, a la alta frecuencia de desechos de tamaños pequeños a muy pequeños, la muy escasa representación de desechos de módulos de anchura-espesor muy espesos y de aquellos que conservan corteza, sugiere la presencia de actividades relacionadas con la formatización y regularización de instrumentos, y en menor proporción con el mantenimiento de filos (Martínez et al. 1997-1998). La materia prima más representada es la cuarcita con ca. $95 \%$. 
El análisis de los materiales faunísticos muestra que el principal recurso explotado ha sido el guanaco (Lama guanicoe NMI '=12). Aunque en menor proporción también están representadas otras especies más pequeñas como el venado de las pampas (Ozotoceros bezoarticus, NMI=3) y la vizcacha (Lagostomus máximus, NMI=6) (Martínez et al. e.p.).

Los resultados alcanzados hasta el momento a través del análisis tecno-morfológico del material lítico y de los estudios taxonómicos, anatómicos y tafonómicos que se han realizado sobre el material óseo recuperado, apoyan la idea de que este contexto representa un sitio de actividades específicas relacionado principalmente a la caza y procesamiento primario de guanaco. Paso Otero 3 representa un sitio donde uno o varios grupos humanos, ya sea en un evento o en más de uno, habrian permanecido durante un corto lapso. Dado que en este trabajo se busca establecer la función artefactual es importante destacar que durante esta/s corta/s estadía/s se habrían llevado a cabo diversas actividades en las cuales habría sido utilizado el instrumental lítico objeto de este estudio: la caza del guanaco, su procesamiento primario, la división de los animales en unidades de trozamiento primarias, posiblemente el consumo de algunas partes blandas y fundamentalmente se realizó un consumo intensivo de médula ósea (Martínez 1999).

\section{ANÁLISIS TECNO-MORFOLÓGICO DE LOS MATERIALES LITICOS}

La superficie total excavada hasta el momento en el sitio es de $24 \mathrm{~m}^{2}$ donde se recuperaron 636 artefactos líticos, los cuales fueron agrupados en desechos de talla $(\mathrm{N}=596: 93,6 \%)$, núcleos $(\mathrm{N}=2: 0,4 \%)$, instrumentos $(\mathrm{N}=37: 5,8 \%)$ y un percutor $(\mathrm{N}=1: 0,2 \%)$.

La caracterización de los instrumentos se realizó siguiendo los lineamientos generales de Aschero $(1975,1983)$ con algunas modificaciones. En este sentido, fueron tomados los siguientes atributos: materia prima, tamaño, módulos longitud-anchura y anchura-espesor, cantidad de filos por grupo tipológico, presencia de filos complementarios, forma base, serie técnica, situación de los lascados, posición del filo, forma y dirección de los lascados de formatización, conformación del borde, regularidad del borde y/o de la arista activa, estado del filo, ángulo del filo, sección del filo, forma geométrica del filo y estado de fragmentación.

1 Número Mínimo de Individuos. 
En Paso Otero 3 los instrumentos son en su mayoría unifaciales confeccionados sobre lascas angulares, de arista y planas, con filos de sección asimétrica con microrretoque y/o retoque marginal y la mayoría de ellos se encuentran fracturados. Solo en tres casos se identificaron instrumentos compuestos que presentan filos correspondientes a grupos tipológicos distintos (en este caso para la clasificación se tuvo en cuenta el filo más formatizado). Los grupos tipológicos más representados son los filos con bisel asimétrico $(\mathrm{N}=14)$, seguidos por las raederas $(\mathrm{N}=9)$, los raspadores $(\mathrm{N}=6)$, los fragmentos no diferenciados de artefactos formatizados $(N=4)$, los litos no diferenciados modificados por uso $(\mathrm{N}=2)$, un unifaz $(\mathrm{N}=1)$ y por último, un fragmento de filo de artefacto formatizado ( $\mathrm{N}=1)$ (Gráfico 1). Entre los instrumentos, como en el resto de los artefactos, la materia prima predominante es la cuarcita de grano fino con $89,2 \%$, seguida de la calcedonia y el sílice con $2,7 \%$ cada uno y las indeterminadas con $5,4 \%$.

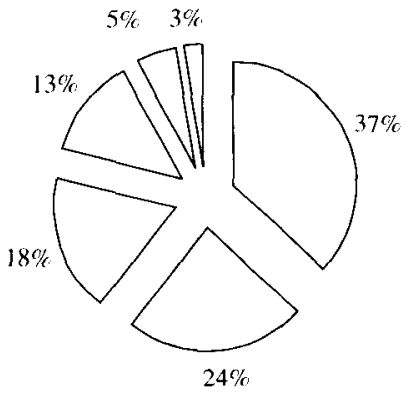

Filo bisel asimétrico

$\square$ Raspador

$\square$ Lito no diferenciado modificado por uso $\square$ Raedera

口Fragmento no diferenciado de artefacto formatizado 口Unifaz.

Con el fin de analizar la relación entre los aspectos tecno-morfológicos y funcionales se seleccionó una muestra al azar de 17 piezas que representa un $42,5 \%$ del total de instrumentos. De acuerdo a los grupos y subgrupos tipológicos, los instrumentos se agruparon en: 6 raederas (tres de ellas con filo lateral, dos con filos convergentes y una con filo bilateral); 2 raspadores (uno con filo frontolateral y uno con filo lateral); 8 filos con bisel asimétrico (cinco de ellos con filo lateral, dos bilateral, uno frontal) y 1 fragmento de filo de artefacto formatizado (ver Tabla 1). 


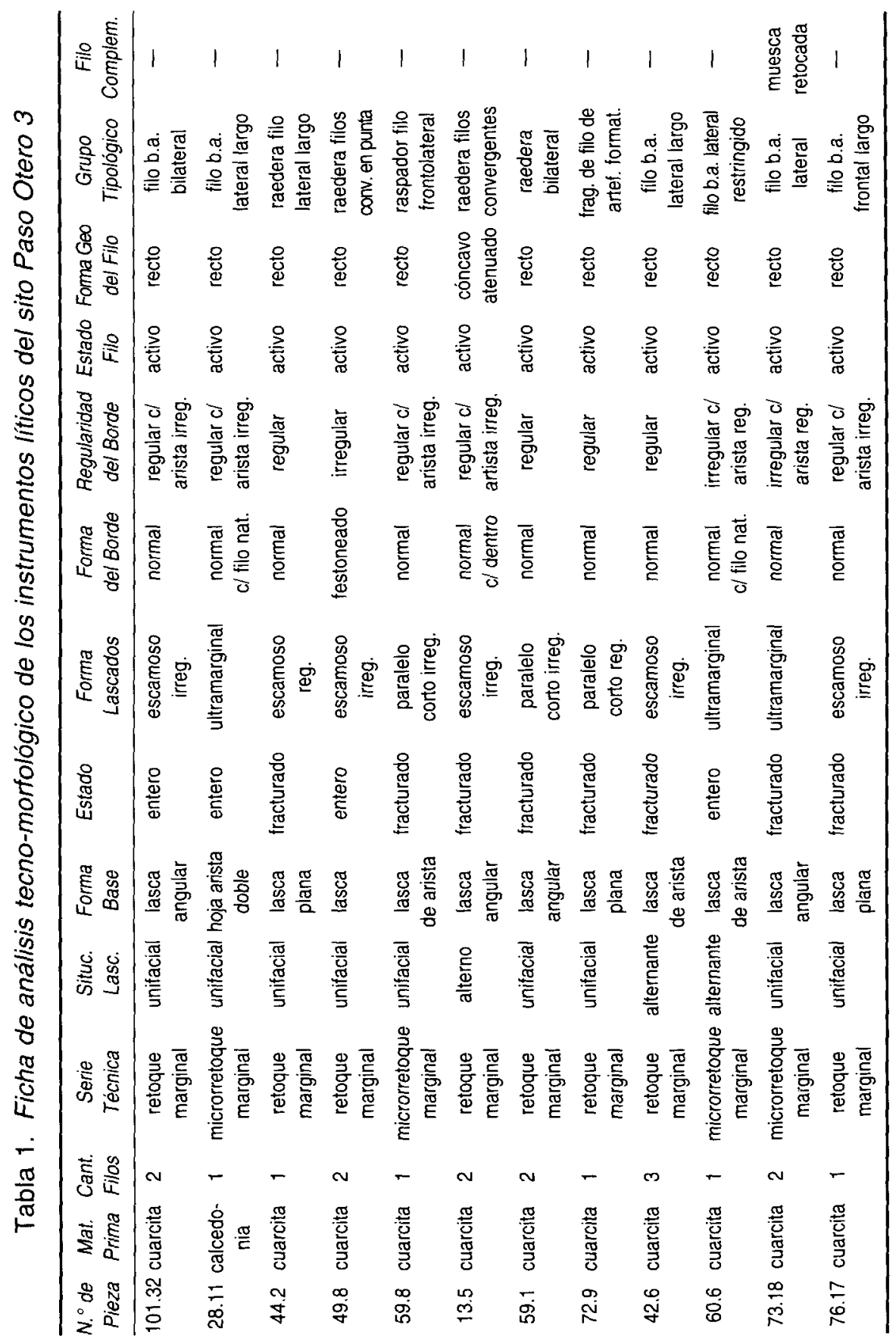




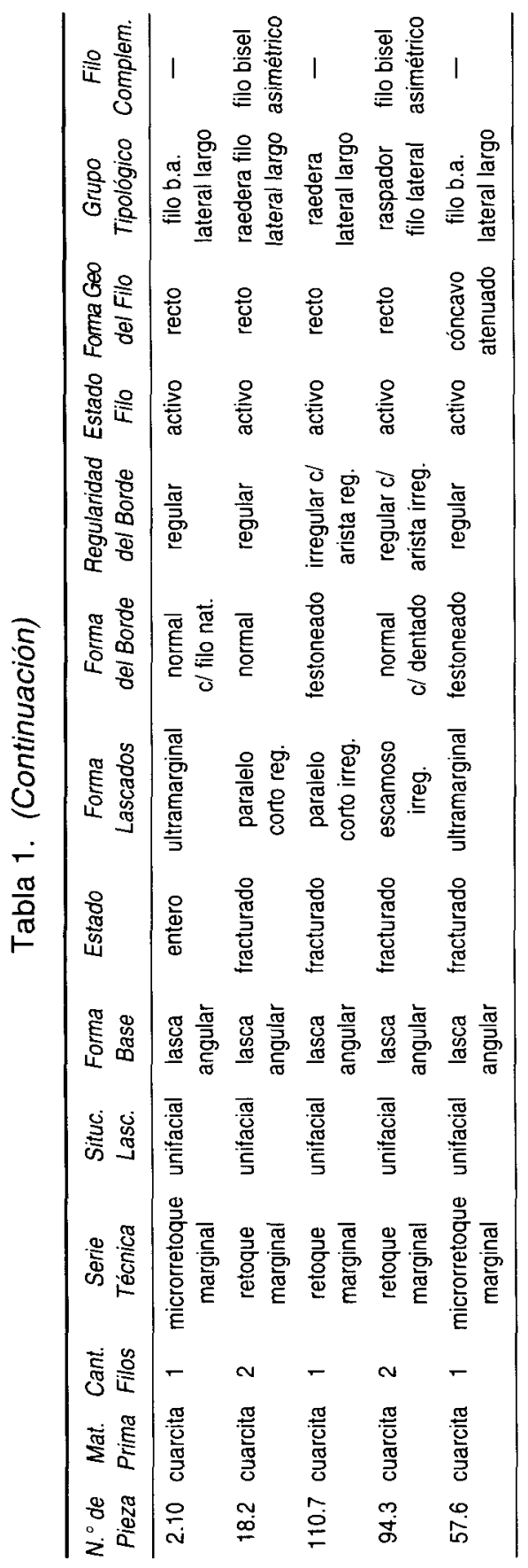


Analizando los datos de la Tabla 1, relacionados a la cantidad de filos, se observa que los instrumentos de mayor frecuencia son los que poseen uno y dos filos y sólo uno de tres filos, sumando un total de 26 filos. En el análisis de la forma de los lascados se observa que en todos los instrumentos está representado el escamoso regular e irregular, sólo los filos de bisel asimétrico presentan lascados ultramarginales, mientras que las raederas y raspadores tienen lascados paralelos cortos. La forma del borde que presenta mayor frecuencia es la normal, en algunos casos combinada con filo natural y dentado sumario. En todos los casos los filos están activos y no se registran evidencias macroscópicas de reactivación de los mismos.

Como formas base se emplearon lascas de distintos tipos sobre las cuales, sin previa preparación, se confeccionaron filos de bisel asimétrico con microrretoque y retoque marginal. En el caso de las raederas y raspadores, no se registran evidencias de trabajo sobre las caras de las piezas que indiquen una formatización general de las mismas, sino que solo se retocaron los bordes. En relación a este punto, se destaca que un gran porcentaje de los instrumentos posee el borde o la arista irregular, lo que sugiere por un lado que no habría una selección de formas base especificas, y por otro que no habría una gran inversión de energía en la regularización de los mismos. La forma geométrica del filo que se registra con mayor frecuencia es la recta y sólo en dos casos se presentan filos cóncavos atenuados.

En el material en general y particularmente entre los instrumentos, se observa un alto índice de fragmentación. Es interesante remarcar que no se evidencian bulbos de origen de las fracturas por lo cual se descarta que éstas sean intencionales (Bernaldo de Quirós et al. 1981). Esto puede deberse fundamentalmente a accidentes durante el proceso de talla o producidas por agentes postdepositacionales, y en un grado menor pueden haberse producido durante el uso, dado que en la muestra se ha registrado sólo una pieza cuyos retoques se ven interrumpidos por una fractura posiblemente producida durante su utilización.

Este contexto sugiere que existe una marcada tendencia hacia la elaboración de instrumentos situacionales que una vez utilizados han sido descartados en el lugar (ver Nelson 1991 para una distinción de instrumentos situacionales de expeditivos). Es importante señalar que se registra una gran variabilidad entre las piezas atribuidas a un mismo grupo tipológico, es decir que no existe una estandarización dado que en general, no se observan atributos compartidos por las piezas que integran cada uno de los grupos. En este sentido, con respecto al estudio de la forma y diseño diferenciamos en primera instancia a los instrumentos formales de 
los informales. Según Andrefsky (1994) existe una distinción entre aquellos instrumentos en los cuales se ha invertido escaso esfuerzo y tiempo en su producción («informales») y aquellos cuya producción incluyó una mayor inversión de tiempo y esfuerzo («formales»). Por instrumentos formales se entiende en este trabajo a aquellos que presentan un diseño específico, repetitivo. En este sentido, y para dar algunos ejemplos del Área Interserrana Bonaerense, las raederas dobles convergentes, los raspadores frontales, las puntas de proyectil triangulares pequeñas, etc. estarian involucrados en este tipo de artefactos, aunque su forma puede presentar variaciones importantes debidas a los diferentes estadios de reducción ( $i$. e. trayectoria de cada uno de los artefactos) que ellos pudieron haber experimentado. Los instrumentos informales serían aquellos productos de talla confeccionados sobre formas bases que presentan un rango de variación importante, en los cuales las únicas modificaciones producidas son microrretoques y retoques marginales (ver Andresfsky 1994: 22, Young 1994: Tabla 1). En el caso de los instrumentos de Paso Otero 3 la mayoria se incluyen en la categoria de informales, ya que las formas bases presentan un rango de variación importante y sobre las cuales las únicas modificaciones producidas son microrretoques y retoques marginales de extensión variable.

\section{ANÁLISIS MICROSCÓPICO DE RASTROS DE USO}

A partir de la aplicación del análisis funcional de base microscópica a los instrumentos líticos resulta posible la determinación de tipos de rastros específicos que se desarrollan durante el uso en la parte del filo que ha estado en contacto con el material trabajado: microlascados, redondeamiento del filo, estrías y micropulidos (Anderson-Gerfaud 1981; Kamminga 1979; Keeley 1977, 1980; Knutsson 1990; Mansur 1999; MansurFranchomme 1983, 1986, 1987; Moss 1978; Plisson 1985; Semenov 1964, 1970; Unger-Hamilton 1984; Vaughan 1981).

La metodología empleada en la observación, identificación y caracterización de los rastros de uso comprende experimentaciones sistemáticas que consisten en la replicación de artefactos líticos y su utilización sobre diversos materiales, en las que se controla el modo y el tiempo de uso y la formación de los rastros microscópicos para registrar qué rastros han sido generados a partir de cada modo de uso y sustancia trabajada. Como paso siguiente, se procede al análisis del material lítico proveniente de contextos arqueológicos, empleando los patrones de rastros significativos como criterio en la identificación funcional (Anderson-Gerfaud 1981; Keeley 1980; Mansur 1999; 
Mansur-Franchomme 1983, 1986, 1987; Plisson 1985; 1986; Semenov 1964; Vaughan 1981).

Los criterios analíticos empleados comprenden básicamente el tipo de materia prima, las series de rastros microscópicos desarrollados por el uso (i. e. microlascados, grado de redondeamiento del filo, estrías y micropulidos), las variables que intervienen en la caracterización de cada uno de ellos (para las estrías: presencia, longitud, orientación, tipo, disposición; para los micropulidos: presencia, situación, brillo, espesor, distribución, extensión, grado de desarrollo, entre otros), los atributos desarrollados por factores tecnológicos (ondas de percusión y estrías, microlascados) y de alteración postdepositacional (lustres de suelo, estrías, pátinas).

Siguiendo estos criterios, como paso previo al análisis del material arqueológico se realizó una fase experimental con instrumentos líticos manufacturados sobre materias primas presentes en los contextos arqueológicos de la Subregión Pampa Húmeda (cuarcitas, calcedonias, sílice, basalto, riolita y toba silicificada, entre otras,) que luego fueron utilizados de diversos modos sobre diferentes materiales (i.e. piel, madera, hueso) con el fin de caracterizar los rastros de uso desarrollados (Leipus 1995, 1999 , e.p.).

Este programa experimental consistió en la replicación de artefactos líticos manufacturados en dos amplios grupos de materias primas: homogéneas y heterogéneas (sensu Mansur 1991, 1999), tomando en cuenta su composición y estructura mineralógica. Las primeras se encuentran conformadas por una matriz que puede ser microcristalina, criptocristalina o amorfa (e.g. sílices, calcedonia) y las segundas por una matriz de similares características y cristales de cuarzo de diversos tamaños cimentados por la misma (e.g. cuarcitas, basaltos, riolitas).

En el caso de las materias primas homogéneas, los criterios de análisis empleados son los desarrollados a partir del estudio de sílices y ftanitas. Las materias primas heterogéneas son observadas mediante un análisis mixto en el que se estudian complementariamente las alteraciones que se producen por uso en la superficie de fractura de los cristales y en la matriz. La matriz, se analiza tomando los criterios desarrollados para sílice y ftanitas, mientras que los cristales de cuarzo se observan teniendo en cuenta el patrón de los rastros desarrollados en base al análisis de cuarzo hialino y obsidiana (Mansur 1991, 1999). Cuando son observados en fractura fresca, los cristales de cuarzo, muestran los rasgos tecnológicos de manera muy clara: ondas y estrías que convergen hacia el punto de percusión y/o presión, y a partir de la utilización, estos rastros tecnológicos comienzan a modificarse, tendiendo a desaparecer (Alonso Lima y Mansur 
1986/90; Mansur 1999). Debido a esto, el análisis de los rastros desarrollados por uso se realiza de manera separada, pero la caracterización funcional se fundamenta tomando a los rastros formados sobre ambas superficies (matriz y cristales) de manera conjunta. Como la finalidad de caracterizar los microrrastros de uso en material experimental es crear un marco comparativo para el análisis de artefactos líticos arqueológicos, se han utilizado los dos tipos de materias primas, es decir calcedonias, sílices, tobas silicificadas, cuarcitas de grano fino y grueso, basaltos y riolitas (Leipus 1995).

La colección experimental se encuentra conformada por 118 artefactos, manufacturados mediante percusión directa utilizando percutores duros. Las variables controladas durante los experimentos de uso han sido: materia prima, modo y tiempo de uso, ángulo de ataque, sustancia trabajada, estado, forma geométrica y ángulo del filo, empleo de sustancias abrasivas y presencia de humedad. El tiempo de uso varió en función del desarrollo de los rastros, y por esta razón, los tiempos de uso oscilaron entre 5', 10', 15', 30' y 60', con la finalidad de registrar los intervalos y el grado de desarrollo máximo de los rastros para cada sustancia y modo de uso específico. Las sustancias trabajadas, han sido gramíneas, maderas de diversas durezas como tala, algarrobo y seibo, hueso, carne, tendones, grasa y periostio de vaca y liebre, pieles de nutria, conejo y liebre, tanto en estado seco, fresco y remojado, en acciones de corte, aserrado, raspado, alisado, cepillado y perforado (Leipus 1995, 1999, e.p.).

Además de la serie destinada a experimentos de uso, se construyeron dos series complementarias con el fin de observar, caracterizar y diferenciar los rastros microscópicos producidos por factores tecnológicos durante el proceso de talla y postdepositacionales como acción de pisoteo, contacto con sedimento, etc. (Leipus 1995).

Los instrumentos ópticos empleados fueron una lupa binocular Iroscope YZ-6 y dos microscopios: uno petrográfico Nikon y uno metalográfico Olympus empleando diversos aumentos (entre 50 y $200 \mathrm{X}$ ). Las piezas arqueológicas se limpiaron con una solución de ácido clorhídrico al $5 \%$ con la finalidad de extraer los sedimentos adheridos en particular carbonatos y además, se empleó alcohol etílico para mantenerlas limpias durante su manipulación en el microscopio.

Es importante aclarar que, si bien a través del análisis tecno-morfológico se identificaron 26 filos, a partir del análisis funcional solo se diferenciaron 25. Esta diferencia en la cantidad de filos resulta de una pieza que fue clasificada en forma distinta por ambas vías de análisis. 
Por un lado, por sus características tecno-morfológicas, fue clasificada como un artefacto compuesto, por presentar un filo en raspador y un filo bisel asimétrico, y por otra parte, estudiando los rastros microscópicos de uso, se determinó la presencia de un único filo.

Por tratarse de artefactos líticos provenientes de un contexto arqueológico, y con la finalidad de arribar a la caracterización funcional de los mismos se emplearon cuatro categorías que incluyen (Alonso Lima y Mansur 1986/90):

- Filos con utilización segura: son aquellos que no presentan alteraciones post-depositacionales y la identificación de rastros microscópicos permite afirmar que efectivamente fueron utilizados, independientemente de que sea posible establecer el tipo de material trabajado y/o el modo de uso.

- Filos con utilización probable: son los que presentan rastros de uso conjuntamente con alteraciones superficiales que los modifican sustancialmente y que por lo tanto no es posible identificar el modo de uso ni el material trabajado.

- Filos con utilización posible: son aquellos filos retocados que no presentan alteraciones post-depositacionales y que por sus características tecno-morfológicas pueden haber sido usados, pero no se distinguen rastros microscópicos de uso.

- Filos sin utilización: son los filos naturales que presentan claros indicios de no haber sido utilizados.

A partir del análisis microscópico, se registró la presencia de rastros de uso seguro en 23 de los 25 filos identificados. Los dos filos restantes fueron clasificados como con uso probable y posible ya que no se observaron rastros definitorios desarrollados por su utilización (Tabla 2). En este sentido una de las piezas (28.11), un filo bisel asimétrico manufacturado sobre calcedonia, fue clasificada como de uso probable ya que presentó un alto grado de alteración postdepositacional, causada básicamente por la acción de partículas sedimentarias. En tanto que, un filo bisel asimétrico lateral, que corresponde a un filo complementario de una de las piezas (42.6), fue clasificado como de uso posible ya que no presenta rastros de uso ni se registraron evidencias de alteración postdepositacional.

A partir de los criterios descriptivos establecidos en el análisis del material experimental, se han establecido los modos de uso y los materiales trabajados con los instrumentos de Paso Otero 3. En algunos 


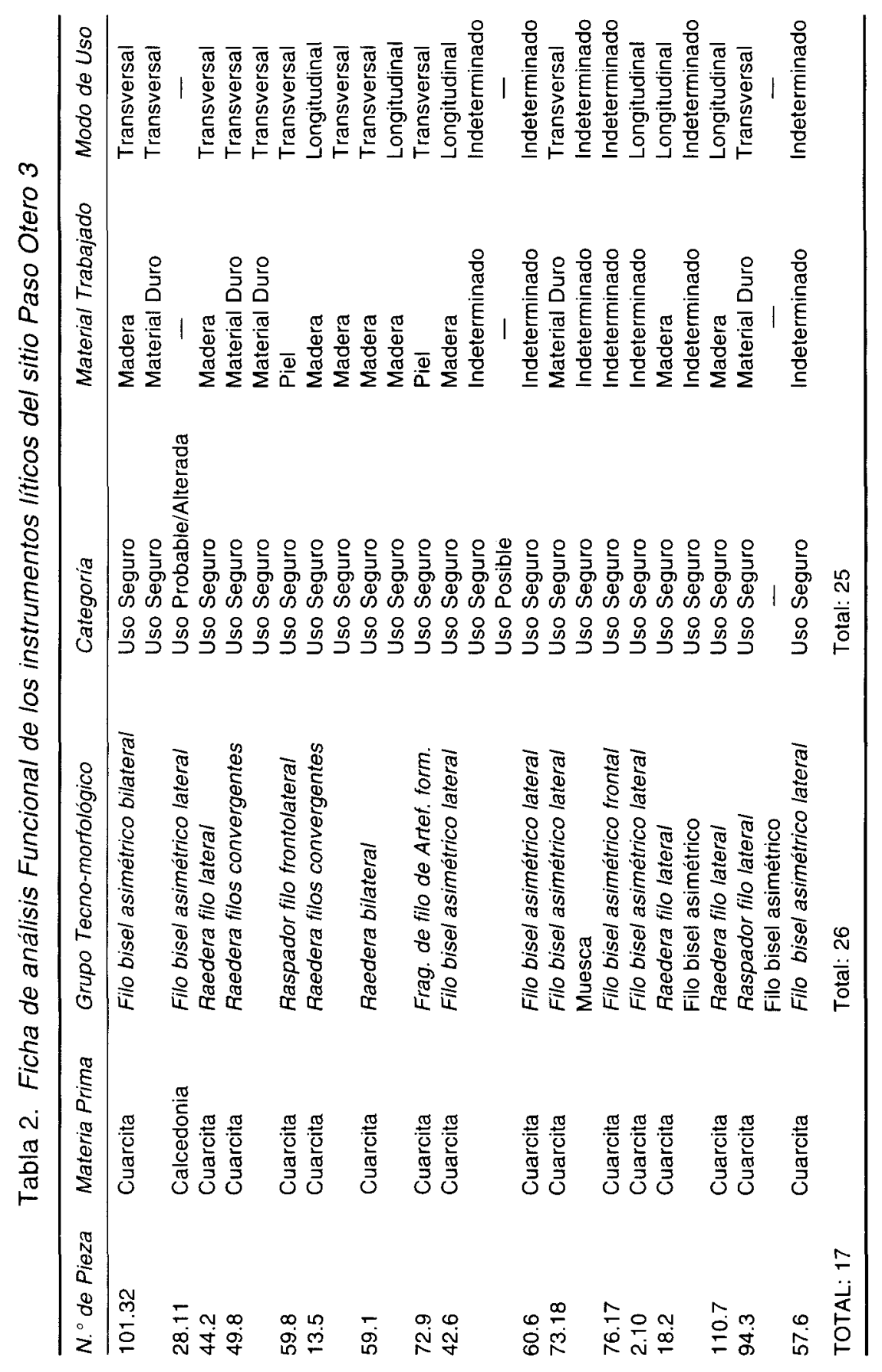


casos, a causa del escaso desarrollo de los rastros, no fue posible determinar con que tipo de acción han sido usados los filos. Otros filos han presentado rastros de uso que, por su grado de desarrollo y localización, no han podido ser asignados al trabajo de ningún material específico y por lo tanto han sido clasificados como de uso indeterminado sobre materiales indeterminados. Esto puede deberse a un escaso tiempo de utilización, a un uso sobre materiales que desarrollan escasos rastros (e.g. carne) (Leipus 1999, e.p.; Mansur-Franchomme 1983, 1986; Mansur 1999).

Los filos que han presentado rastros microscópicos seguros desarrollados por el uso, corresponden a los siguientes grupos tecno-morfológicos: 9 filos en raedera, 2 en raspador, 10 filos bisel asimétrico, 1 muesca y 1 fragmento de filo de artefacto formatizado; todos manufacturados sobre cuarcita (Tabla 2 y 3 ).

Del análisis de los rastros microscópicos de uso registrados en los filos de los instrumentos arqueológicos se dedujo que en 9 filos los rastros fueron el producto de trabajo de madera, en 2 filos estuvieron relacionados al trabajo en piel, en 5 filos fueron producidos por el trabajo sobre materiales duros indeterminados tales como hueso y/o madera - pero que al no estar desarrollados de forma máxima, no pueden ser atribuidos al trabajo de ninguno de los dos- y 7 filos estuvieron empleados sobre materiales indeterminados.

Los modos de uso registrados han sido transversales (11 filos, acción de raspar), longitudinales (6 filos, corte y aserrado) y modos de uso no determinados ( 6 filos). No se observaron casos de superposición de rastros de uso producto del trabajo de más de un material, como así tampoco por dos tipos de modos de uso diferentes.

Para realizar trabajos transversales se han utilizado: 5 filos en raedera, 2 en raspador, 3 filos bisel asimétrico y 1 fragmento de filo de artefacto formatizado; para las acciones longitudinales se usaron 4 filos en raedera y 2 filos bisel asimétrico. Por último, se emplearon 5 filos bisel asimétrico y 1 muesca en trabajos indeterminados.

En cuanto a la relación entre grupos tecno-morfológicos, modos de uso y materiales trabajados, se observan las siguientes tendencias (Tabla 3):

- Los filos en raederas han sido usados para trabajar: madera tanto con movimientos longitudinales (Figura 1) (4 filos) como transversales (3 filos), y para trabajar materiales duros con modo de uso transversal (2 filos). 
- Los filos en raspador han sido utilizados con modos de uso transversales sobre piel (Figura 2) (1 filo) y sobre algún tipo de material duro (1 filo).

Los filos bisel asimétrico fueron usados para realizar trabajos longitudinales sobre madera (Figura 3) (1 filo) y algún material indeterminado (1 filo), trabajos transversales sobre algún tipo de material duro (2

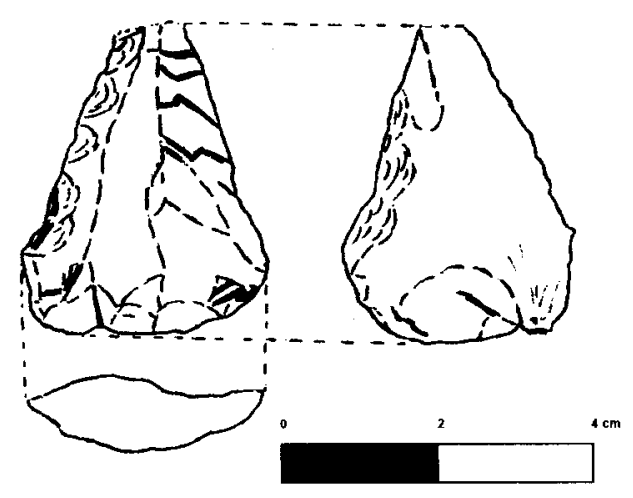

Raedera Filo Lateral PO3.18.2.

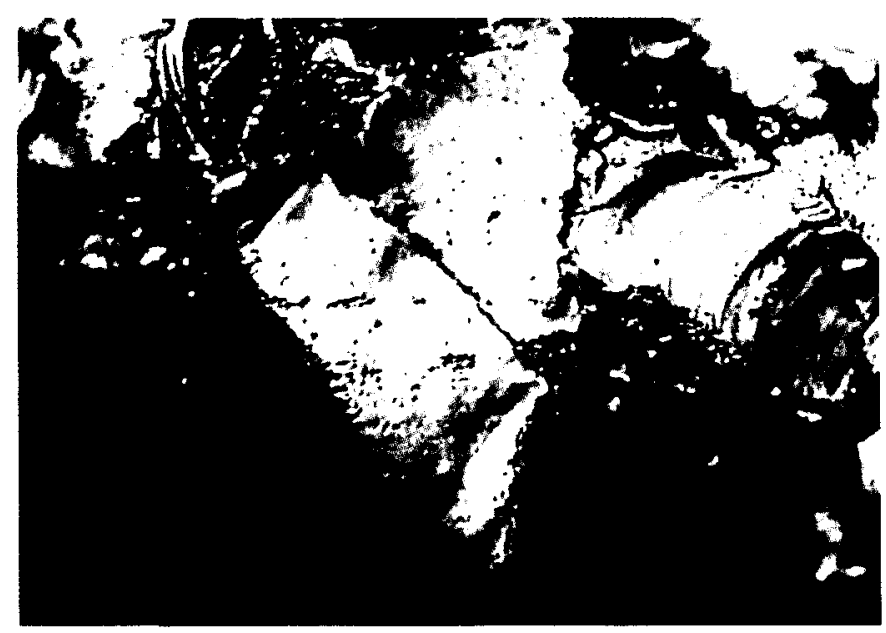

Rastros microscópicos de uso desarrollados por el trabajo longitudinal de madera sobre superficie de fractura de cristales de cuarzo (200 X).

Figura 1 
Forma y función de los instrumentos líticos del sitio Paso Otero $3 .$.

Tabla 3. Análisis Funcional/Grupos Tecno-morfológicos de los instrumentos líticos del sitio Paso Otero 3

\begin{tabular}{|c|c|c|c|c|c|c|}
\hline \multirow{2}{*}{$\begin{array}{l}\text { Dirección de uso/ } \\
\text { Total } \\
\text { material trabajado }\end{array}$} & \multirow[t]{2}{*}{ Raederas } & \multirow[t]{2}{*}{ Raspadores } & \multirow{2}{*}{$\begin{array}{l}\text { Filos Bisel } \\
\text { Asimétrico }\end{array}$} & \multirow{2}{*}{$\begin{array}{l}\text { Frag. de Filo } \\
\text { no diferenciado }\end{array}$} & \multicolumn{2}{|l|}{ Muesca } \\
\hline & & & & & & \\
\hline Longitudinal-madera & 4 & - & 1 & - & - & 5 \\
\hline Longitudinal-indeterminado & - & - & 1 & - & - & 1 \\
\hline Transversal-madera & 3 & - & 1 & - & - & 4 \\
\hline Transversal-piel & & 1 & - & 1 & - & 2 \\
\hline Transversal-material duro & 2 & 1 & 2 & - & - & 5 \\
\hline Indeterminado-indeterminado & - & - & 5 & - & 1 & 6 \\
\hline Total & 9 & 2 & 10 & 1 & 1 & 23 \\
\hline
\end{tabular}

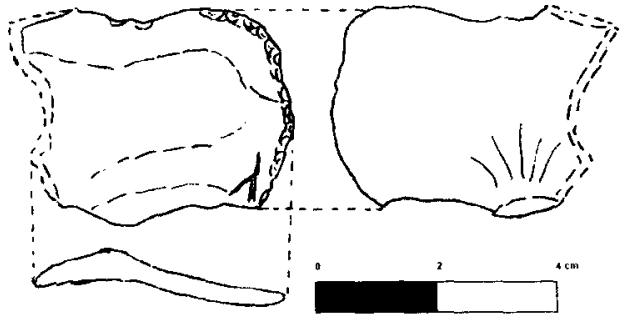

Raspador de filo frontolateral. PO3. 59.8.

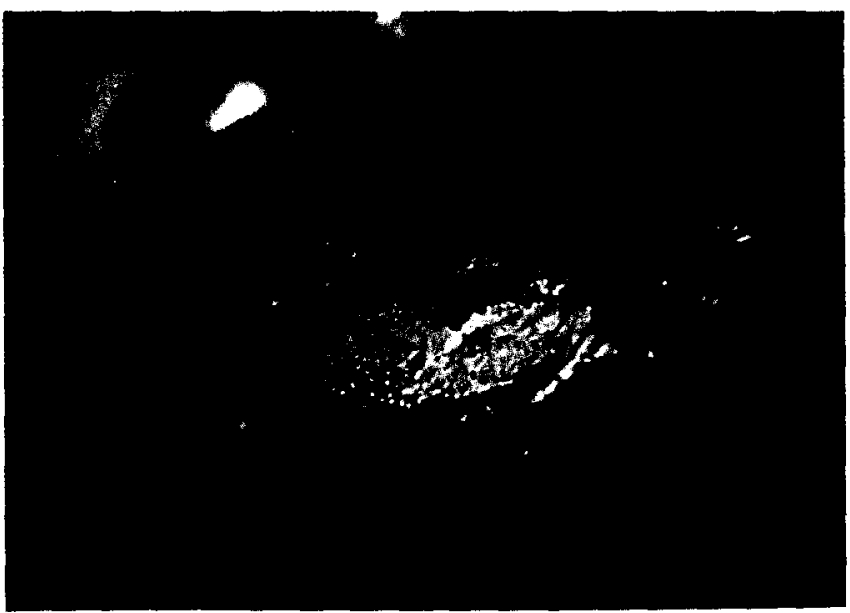

Rastros microscópicos de uso desarrollados por el trabajo transversal de piel sobref superficie de fractura de cristal de cuarzo (200 X).

Figura 2 
filos) y sobre madera ( 1 filo) y sobre materiales indeterminados ejerciendo movimientos indeterminados (5 filos).

- El fragmento de filo de artefacto formatizado fue utilizado para trabajar piel con un modo de uso transversal (Figura 4).

- En el caso de la muesca fue usada sobre material indeterminado con modo de uso también indeterminado.

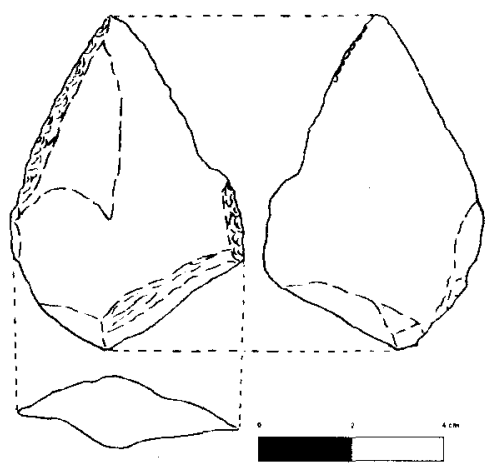

Filo bisel asimétrico lateral PO3.42.6.

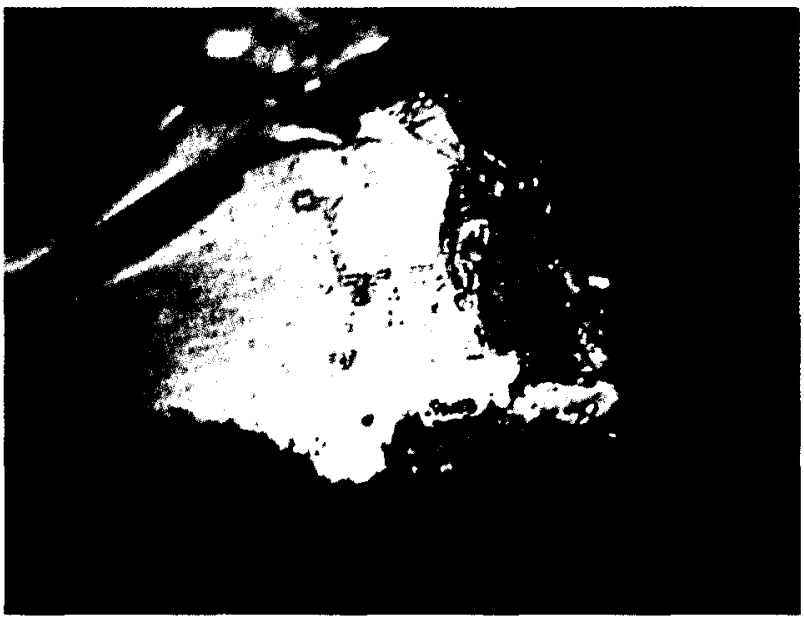

Rastros microscópicos de uso desarrollados por el trabajo longitudinal de madera sobre superficie de fractura de cristal de cuarzo $(200 \mathrm{X})$.

Figura 3 


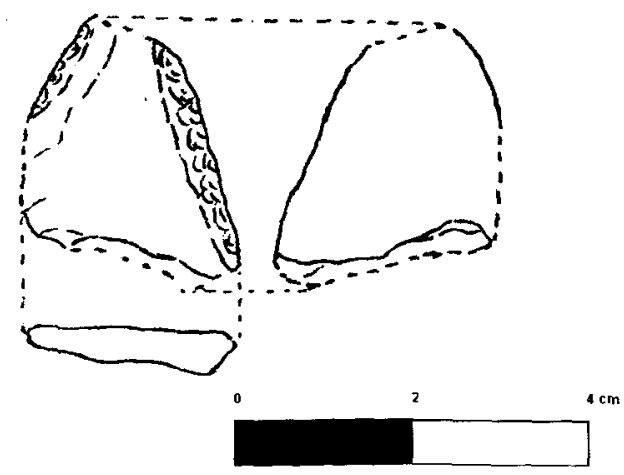

Fragmento de filo de artefacto formatizado. PO3.72.9.

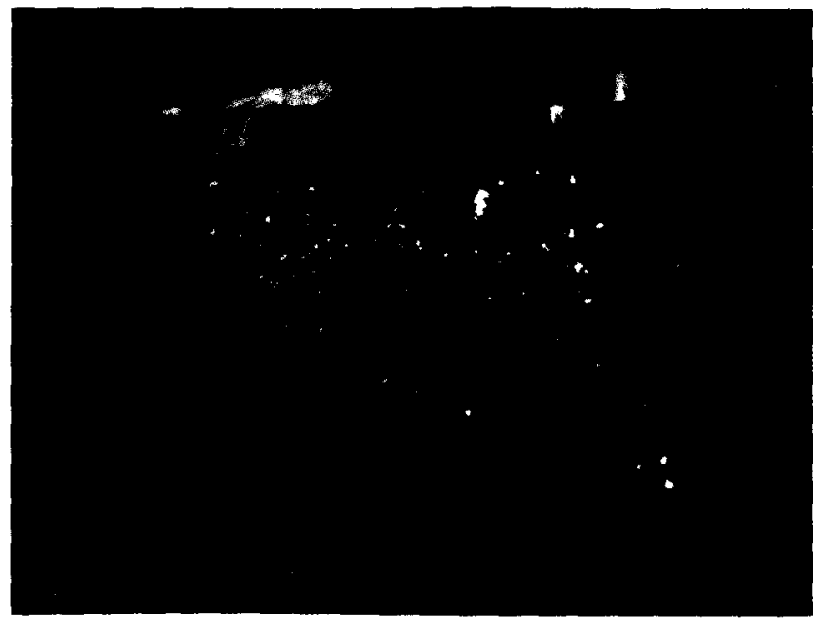

Rastros microscópicos de uso desarrollados por el trabajo transversal en piel sobre amtriz de cimentación $(200 \times)$.

Figura 4

\section{DISCUSIÓN}

A partir de la comparación de los resultados obtenidos de los análisis tecno-morfológico y funcional, se observa que en algunos instrumentos $(\mathrm{N}=6)$ no fue posible determinar el modo en que fueron utilizados los filos. En los casos en que el uso pudo ser diferenciado, se registró una correspondencia entre la función esperada según el grupo tipológico asignado a las piezas y el uso que efectivamente se le dio a las mismas $(N=4)$, en 
otros casos no se da esta correspondencia $(\mathrm{N}=4)$. Por último en las raederas $(\mathrm{N}=9)$ no es posible establecer si se cumple o no esta correspondencia dado que éstas son consideradas como instrumentos multifuncionales (Anderson-Gerfaud 1981:80-82; Grimaldi y Lemorini 1993; Knutsson 1989: 735; Leipus 1997,1999b, ms). Es importante destacar que, aunque la muestra analizada incluye poca cantidad de piezas, existe una gran variabilidad de grupos tecno-morfológicos, de funciones esperadas (teniendo en cuenta el grupo tipológico) y asignadas (en base a los resultados del análisis funcional). En el caso de los raspadores, su uso se asocia generalmente al trabajo de piel con movimientos transversales al filo activo, a los fines de extraer las partículas de carne, grasa, pelos, durante el tratamiento de las pieles (Casamiquela 1978; Gusinde 1986). El análisis funcional de los dos raspadores sugiere efectivamente un modo de uso transversal, aunque uno de ellos fue utilizado para el trabajo de piel y el otro para materiales duros. Por otro lado se observa que el fragmento de filo de artefacto formatizado fue utilizado para trabajar piel con un modo de uso transversal. En consecuencia, aunque este artefacto no pueda incluirse desde el punto de vista tecno-morfológico dentro de una categoría definida, su utilización fue la misma que la de los raspadores.

Por su parte, las raederas han sido consideradas como instrumentos multifuncionales (usadas para distintas actividades como cortar, raspar, etc.), donde la dirección del trabajo sobre distintos materiales puede ser tanto transversal como longitudinal. Los rastros de uso de las raederas analizadas en Paso Otero 3 indican que la dirección del trabajo sobre distintos materiales fue tanto transversal como longitudinal, lo que sugiere que estas fueron utilizadas en diversas actividades. A su vez, los filos bisel asimétrico generalmente están asociados a actividades de corte, especialmente descarne y desposte; sin embargo los resultados del análisis microscópicos indican, al igual que en las raederas, un uso tanto longitudinal como transversal.

Se observa que en algunos casos instrumentos que tecno-morfológicamente asignados a grupos tipológicos diferentes han sido utilizados con la misma cinemática para trabajar un mismo tipo de material. Es decir, que a partir del análisis tecno-morfológico se están considerando diferencias funcionales entre instrumentos que podrían haberse utilizado para realizar las mismas actividades (ver Tabla 3). Por otra parte, mientras los grupos tipológicos fueron definidos a partir del filo principal (aquel que presenta una mayor formatización), el análisis funcional, muestra en algunos casos un mayor uso del filo complementario.

Desde el punto de vista tecno-morfológico se registran artefactos compuestos, considerados de esta manera por presentar filos pertenecientes a 
diferentes grupos tecno-morfológicos en una misma pieza. En el caso del análisis funcional se observa que estos filos fueron usados sobre el mismo material y con el mismo modo de utilización.

Preliminarmente, los resultados expuestos hasta el momento, permiten sugerir que no se establece una correspondencia clara entre la forma y la función de los instrumentos.

En otra escala de análisis, la aplicación del análisis funcional de base microscópica combinado con otra información (e.g. regularización del borde) permitió analizar la intensidad de uso de materias primas y artefactos e indirectamente algunas características del asentamiento. Dadas las características tanto macro como microscópicas del material, se observa un escaso aprovechamiento de las materias primas. Se distinguen formas base o soportes con más de un filo potencialmente utilizable, de los cuales solo se usó o formatizó uno. Además, los filos no fueron utilizados intensamente ya que no se registran filos embotados y hay escaso desarrollo de rastros de utilización, lo cual implica que los instrumentos fueron utilizados durante poco tiempo. Por último no se registra superposición de rastros que indiquen que se estuvieron trabajando dos tipos de materiales distintos con un mismo filo. En este sentido también es destacable que no hay un alto grado de reactivación, patrón que se observa a través de las características de los filos mismos y de acuerdo a la baja frecuencia de lascas de reactivación (Martínez et al. 1997-1998). La evidencia tratada en este último párrafo es coincidente con la idea de que el sitio haya sido ocupado durante una o varias estadías breves y donde se realizaron actividades específicas a través del empleo de instrumentos situacionales. Por lo general, en campamentos base frecuentemente reocupados y asociados a múltiples actividades se produce el reuso de artefactos, situación que estaría evidenciada por estos patrones de rastros de uso superpuestos.

Dada la funcionalidad atribuida a Paso Otero 3, se esperaría que los filos presenten evidencias de procesamiento (i.e. desposte) de materiales blandos como la carne. Sin embargo, no se hallaron evidencias de rastros de trabajo de carne, la ausencia de estos rastros puede deberse a una serie de factores. Por un lado, para que este material desarrolle rastros que se conserven en los filos debe ser trabajado durante un largo tiempo (Leipus 1999, e.p.; Mansur-Franchomme 1983, 1986, Mansur 1999) y en general los rastros de uso de los filos del sitio tienen escaso desarrollo. Además, puede deberse a que para esta actividad hayan sido utilizados filos naturales sin formatización que no fueron incluidos en el análisis funcional.

Sin embargo, y a diferencia de las expectativas iniciales, considerando que Paso Otero 3 es un sitio de matanza y procesamiento primario, es 
importante destacar la elevada representación de filos con rastros que indican el trabajo de madera, $(\mathrm{N}=9)$. Dado que no es común que este tipo de material se conserve en los sitios arqueológicos de la Región Pampeana, en base a la información obtenida hasta el momento no es posible determinar que tipo de artefactos se confeccionaron sobre este material, aunque dado el contexto del sitio, probablemente éstos hayan estado relacionados a la caza y el procesamiento de animales (e. g. astiles, mangos o lanzas de madera).

Entre los instrumentos observados se registraron rastros que indican trabajo en piel. Estos rastros no se deberian al curtido prolongado de las mismas ya que las evidencias que presentan los instrumentos empleados sobre este material indican que no fueron utilizados durante mucho tiempo y que no se han empleado elementos abrasivos. Por lo tanto, sugerimos que se estaban desarrollando actividades vinculadas al procesamiento inicial de las pieles.

Dada la funcionalidad planteada para el sitio, también se esperaban rastros producidos por el trabajo en hueso, aunque no se registraron evidencias claras de trabajo sobre este material. En este sentido, es posible que el material duro sobre el que han sido utilizados algunos de los instrumentos se trate efectivamente de hueso, aunque debe mencionarse la dificultad para distinguir los rastros dejados por el trabajo sobre esos materiales debido a un escaso desarrollo. Sin embargo, la presencia de huellas de corte en el 3,1\% de los huesos (Martínez 1999) avala esta sugerencia. Otra posibilidad podría ser que estos instrumentos utilizados sobre material óseo no hayan sido descartados en el sitio.

\section{CONCLUSIONES}

Sobre la base de las evidencias obtenidas a través de los análisis macroscópicos de restos faunísticos y líticos se propuso que el sitio Paso Otero 3 sería el resultado de actividades de matanza, procesamiento inicial y consumo de Lama guanicoe. En el marco de esta caracterización funcional general, el sector representado por la excavación mostraría sólo una parte del sitio destinada al procesamiento inicial, al consumo de médula ósea, a la elaboración de filos y descarte de ítems óseos y líticos. Esta caracterización del sitio se transformó en el punto de partida para analizar qué conductas específicas pudieron haberse efectuado en este contexto y dos vías analíticas diferentes fueron usadas para evaluar la existencia de tales conductas: análisis tecno-morfológicos y de rastros microscópicos de uso. 
Dentro de los enfoques tecno-morfológicos, las semejanzas formales entre los artefactos líticos recuperados en sitios arqueológicos y los registrados en grupos contemporáneos han servido de base para la asignación de determinadas funciones o usos a determinados instrumentos (ver Gould 1980; Hernando Gonzalo 1995; Hodder 1982; Ravn 1993; Trigger 1992, entre otros). Este supuesto, más allá de la finalidad descriptiva del enfoque, estipulaba que determinadas formas deberían tener un rango de funciones específicas.

Sin embargo, la aplicación de una metodología microscópica de análisis funcional sugiere que en Paso Otero 3 no se observa una relación clara entre las inferencias funcionales provenientes del análisis microscópico y la función que generalmente se asigna a los grupos tipológicos reconocidos. La conclusión más aparente en el caso de Paso Otero 3 es que salvo el caso de los raspadores no se utilizan formas especiales para realizar alguna actividad. Sin embargo, esta misma tendencia es observada en algunos materiales líticos de otros sitios del área Interserrana Bonaerense, en particular en artefactos de los Componentes Medio e Inferior del sitio Arroyo Seco 2 y de Laguna Tres Reyes 1 (Leipus 1997, 1999a y b, ms). En consecuencia, puede plantearse que hay una baja correspondencia entre forma y función, lo que dificulta la inferencia de las actividades desarrolladas en los sitios arqueológicos sólo a partir del análisis tecno-morfológico de los conjuntos artefactuales.

No obstante, la falta de correspondencia entre la forma y función esperada de ciertos artefactos, el análisis funcional ha permitido identificar que el rasgo más frecuentemente registrado en los filos se asocia al trabajo de madera. Este patrón resulta interesante porque otro de los supuestos o hipótesis que se mantenía de acuerdo a la función del sitio fue que los rastros desarrollados por el trabajo en carne serían los más frecuentes. El hallazgo de rastros microscópicos relacionados al trabajo en madera en Paso Otero 3 (aunque es difícil aún precisar que artefactos se manufacturaron), es de suma importancia dentro del contexto del área interesaran Bonaerense ya que esta sustancia no tiene generalmente un correlato material directo en el registro arqueológico. Una excepción es el sitio arqueológico la Olla 1 y 2 , donde fueron registrados abundantes restos macroscópicos de vegetales e instrumentos de madera (Bayón y Politis 1996). En este sentido, es importante mencionar que en La Moderna, un sitio de matanza ubicado en el área Interserrana Bonaerense, también se registraron a través del análisis funcional evidencias de trabajo en madera (Politis y Olmo 1986; Politis y Gutiérrez 1998).

Es interesante notar que la aplicación de esta metodología funcional a los conjuntos pampeanos comenzó a ser aplicada bajo la premisa que, 
idealmente, intentaba descubrir una asociación específica entre un tipo de artefacto y su función. Sin embargo, la aplicación de la misma ha llevado a descubrir la utilización en el contexto sistémico de recursos que generalmente no son registrados en el contexto arqueológico (sensu Schiffer 1972). Es decir, los resultados obtenidos en La Moderna y en Paso Otero 3 dieron lugar al conocimiento de que en esos sitios de matanza y desposte otra materia prima, como la madera, había estado siendo usada.

A la luz de estos resultados es importante destacar que el análisis funcional no sólo ha sido útil a los fines comparativos de analizar la relación "forma-función" de determinados artefactos líticos, sino que agrega una dimensión ligada al tipo de cinemática y a la sustancia trabajada. Cabe destacar que dado que no siempre es posible registrar rastros de uso en los instrumentos, el análisis tecno-morfológico sumado a otra información contextual sigue siendo una herramienta útil para tener en cuenta en el análisis de los materiales líticos. Esta aproximación provee datos que contribuyen al entendimiento de la explotación del ambiente, ya sea de las materias primas líticas como de los recursos de subsistencia y por lo tanto ayudan a complementar aspectos relacionados con la funcionalidad del sitio.

Sin embargo, esta falta de correspondencia entre la forma y la función esperada de acuerdo al análisis tecno-morfológico debe ser analizada de acuerdo a:

1) El sesgo que cada metodología aporta a la comprensión de un fenómeno común (e.g. a igual intensidad de uso, mayor posibilidad de preservación de rastros en el caso del trabajo sobre materiales óseos que sobre carne).

2) La idea de que los contextos arqueológicos se forman bajo circunstancias particulares y contingentes, donde no es siempre posible esperar correspondencias ajustadas.

Esto último significa que los "estándares» finales de comparación para las correspondencias pueden variar y su construcción depende de la generación de información contemporánea relevante a nivel arqueológico y regional. Es decir, que con el conocimiento arqueológico derivado de ambas fuentes (análisis tecno-morfológicos y funcional) en situaciones (e.g. sitios de caza producidos por cazadores-recolectores) y ambientes particulares (e.g. Área Interserrana) puede lograrse la aplicación de una escala de comparación más adecuada que escape a las limitaciones de la analogía formal (ver Wylie 1982, 1985; Yacobaccio 1991) y permita determinar cuál es la variabilidad dentro de las propiedades objetivas de los 
artefactos y cuales son los criterios de relevancia utilizados para la confrontación en contextos particulares.

\section{AGRADECIMIENTOS}

A los Licenciados Rafael Curtoni y Patricia Madrid por la lectura atenta del manuscrito y sus valiosos comentarios. Al Licenciado Jorge Moirano por sua asesoramiento en la gráfica. Este trabajo fue realizados en el marco del Proyecto INCUAPA de la Facultad de Ciencias Sociales de la UNCPBA.

\section{REFERENCIAS CITADAS}

Alonso Lima, M. y M. E. Mansur (1986/90): Estudo traceológico de instrumentos em quartzo e quartzito de Santana Do Riacho (M. G.). Revista do Museu de Historia Natural de Minas Gerais, Vol. 11:173-190. Belo Horizonte. UFMG.

ANDERSON-GERFAUD, P. (1891): Contribución métodologique a l'analyse des microtraces d'utilisation sur les outils préhistoriques. Thése de Doctorat, Univ. Bordeaux I. $314 \mathrm{p}$.

ANDREFSKY, W. (1994): Raw-Material availability and the Organization of the technology. American Antiquity, 59 (1): 21-34.

ASCHERO, C. (1975): Ensayo para una clasificación morfologica de artefactos liticos. Informe CONICET. ms.

- (1983): Registro de códigos para atributos descriptivos aplicados a artefactos líticos. informe CONICET. ms.

BAyón C. y G. POLITIS (1996): Estado actual de las investigaciones en el sitio Monte Hermoso 1 (Prov. de Buenos Aires) Arqueologia, 6:83-115.

Bernaldo de Quirós, $F$. et al. (1981): Proyecto de análisis técnico para las industrias líticas. Trabajos de Prehistoria, 38:9-37. Madrid, España,

BINFORD, L. (1980): Willow smoke and dogs tails: Hunter-gatherer settlements sistems and archaeological site formation. American Antiquity, 45 (1): 4-20.

Casamiquela, R. (1978): Temas patagónicos de interés arqueológico. Ill. La técnica de la talla del vidrio. Relaciones de la Sociedad Argentina de Antropología, T. XII: 213-233.

Fidalgo F., F. De Francesco y U. Colado. (1973): Geología Superficial en la Hojas Castelli, J. M. Cobo y Monasterio (Pcia. de Buenos Aires). Actas del Quinto Congreso Geológico Argentino IV: 27-39. Bs. As.

Franco, N. y F. Carballo Marina (1993): Variabilidad en raederas en el Lago Argentino (Santa Cruz, Argentina). Arqueología, 3: 213-232.

GaLLAGHER, J. (1979): Contemporary stone tools in Ethiopia: implication for archaeology. Journal of Field Archaeology, 4: 407-414.

GrimALDI, S. y C. LEMORINI (1993): Retouche spécialiseé et/ou chaîne de ravivage?. Les "racloirs" moustériens de la Grotta Breuil (Monte Circeo, Italie). Traces et Fontions: les gestes retrouvés. Colloque International de Liége, Editions ERAUL, Vol. 50: 67-78.

Gould, R. (1973): Use wear on western desert aborigines stone tools: a replay to Messrs, Hayden and Kamminga. Lithic Technology, 2: 9-13.

- (1980): Living Archaeology. Cambridge University Press, Cambrige.

Gould, R., D. KOSTER y A. SONTZ (1971): The lithic assamblage of the western desert aborigines of Australia. American Antiquity, 36 (2): 149-169.

Gusinde, M. (1986): Los indios de Tierra del Fuego. Tomo I, Vol. I. Buenos Aires, CAEA.

HAYDEN, B. (1979): Paleolithic reflections. Lithic Technology and etnographic excavations among Australian Aborigines. Australian Institute of Aborigines Studies. Camberra. 
Hayden, B. y Kamminga, J. (1973): Gouid, Koster and Sontz on microwear. A critical Review. Lithic Technology, 1-2:.3-8.

Hernando Gonzalo, A. (1995): La etnoarqueología, hoy una vía eficaz de aproximación al pasado. Trabajos de Prehistoria, 52, Nro. 2:15-30.

Hester, T. y R. HeIzER (1973): Arrow points or knives? Comments on the proposed functions of "Stockton points". American Antiquity, 38: 343-350.

Hester, T., D. Gilbow y A. AlbeE (1973): A functional analysis of "Clear Fork» artifacts from the Rio Grande Plain, Texas. Amnerican Antiquity, 38: 90-96.

Hodder, I. (1982): The Present Past. B. T. Batsford Ltd, London.

JOHNSON, J. (1989): The utility of production trayectory modeling as a framework for regional analysis. Alternative Approaches to Lithic Analysis. D. Henry y G. Odell Eds.. Archaeological Papers of the American Anthropological Association, Number 1:119-138. Washington D.C..

KAMMINGA, J. (1979): The nature of use-polish and abrasion smoothing on stone tools. Lithic Use-wear Analysis. B. Hayden ed. 143-157 p. Academic Press, New York. Keeley.

- (1977): An experimental study of microwear traces on selected British Plaeolithics implements. PH. D Thesis, University of Oxford.

- (1980): Experimental determination of stone tools use: a microwear analysis. University of Chicago Press. Chicago. $212 \mathrm{p}$.

KNUTSSON, K. (1989): Analyse tracéologique des outillages de quartz: les enseignements du site Néolitique Moyen-tardif de Bjurselet, Suede Septentrionale. L'Anthropologie, Tome 93, N. ${ }^{\circ}$ 3: 705-738.

- (1990): A New Lithic Scene. The Archaeological context of used tools. The interpretative possibilities of microwear studies: 15-30. Societas Archaeologica Upsaliensis, Uppsala. Suecia.

LEIPUS, M. (1995): Experimentación aplicada al análisis funcional de artefactos líticos de las áreas Interserrana y Serrana de Ventania, provincia de Buenos Aires. Actas de las II Jornadas para Jóvenes Investigadores en Antropología. INAPL, UBA.

- (1997): Manufactura y uso de los artefactos líticos del sitio Arroyo Seco 2, partido de Tres Arroyos, provincia de Buenos Aires. Presentado en el XII Congreso Nacional de Arqueologia Argentina, La Plata. 24 p.

- (1998): Análisis de los modos de uso prehispánicos de las materias primas líticas en el Sudeste de la Región Pampeana: Una aproximación funcional. Informe de Avance de Beca de Perfeccionamiento al CONICET. 1998. 299 p. m.s

- (1999a): Análisis Funcional: caracterización de los microrrastros de uso en materias primas líticas de la Región Pampeana. Actas del XII Congreso Nacional de Arqueología Argentina. Tomo I: 345-353. Editorial de la UNLP.

- (1999b): Materias primas, tecnología y función: Análisis comparativo de los instrumentos líticos de los Componentes Medio e Inferior del sitio Arroyo Seco 2, provincia de Buenos Aires. ms. 102 p. e.p. Análisis de rastros de uso experimentales en materias primas líticas de la Región Pampeana. Simposio Nuevos Aportes y Desarrollo de Técnicas para la Arqueologia. Actas del $I X$ Congreso Nacional de Arqueologia Uruguaya, Colonia del Sacramento: 20.

MAGNE, M. (1989): Lithic Reduction Stage and Assemblage Formation Precesses. Experiments in Lithic Technology S. Amick y R. Mauldin Eds: 15-31 BAR International Series 528, Oxford.

Mansur, M. E. (1999): Análisis Funcional de instrumental lítico: problemas de formación y deformación de rastros de ușo. Actas del XII Congreso Nacional de Arqueologia Argentina, Tomo I: 355-366. La Plata.

- (1991): Microwear on quartz crystals and obsidian: its contribution to use wear analysis on heterogeneous materials. Presentado en VI International Flint Symposium, Madrid.

Mansur-Franchomme, M. E. (1983): Traces d'utilisation ef technologie lithique: Exemples de la Patagonie. Thèse de 3ème Cycle, Université de Bordeaux I. 516 p.

- (1986): Microscopie du matériel lithique préhistorique. Traces d'utilization, altérations naturelles, accidentelles et technologiques. Cahiers du Quaternaire Nro. 9, CNRS: 1-283.

- (1987): El análisis funcional de artefactos líticos. Cuadernos Serie Técnica, N. ${ }^{\circ}$ 1: 1:42. INA, Buenos Aires.

Martínez, G. (1994): Ocupaciones Arqueológicas en el Curso Medio del Río Quequén Grande (Pdos. de Necochea y Lobería, Pcia. de Buenos Aires). La Arqueología Pampeana en los '90. G. Politis y M. Berón Editores. 71-84 p. INCUAPA y Museo de Historia Natural de San Rafael.

(1999): Tecnologia, subsistencia y asentamiento en el curso medio del Rio Quequén Grande: un enfoque arqueológico. Tesis Doctoral de la Facultad de Ciencias Naturales y Museo-UNLP. 
Martínez, G. y G. Gómez e.p.Evaluación preliminar de los Procesos de Formación del Sitio Paso Otero 3 a través del estudio de la distribución estratigráfica de elementos pertenecientes a roedores y dasipódidos. Presentado en el IX Congreso Nacional de Arqueología Uruguaya. Colonia del Sacramento. Junio de 1997.

martinez, G., Messineo, P., E. Piñeyro, C. Kaufmann y P. Barros : e.p. Análisis preliminar de la estructura faunística del sitio Paso Otero 3 (Pdo. de Necochea, Pcia. de Buenos Aires, Argentina. Presentado en el simposio Nuevos Aportes y Desarrollo de Técnicas para la Arqueología. IX Congreso Nacional de Arqueología Uruguaya. Colonia del Sacramento. Junio de 1997.

Martínez, G., C. Landini y M. Bonomo (1997-1998): Análisis de los artefactos líticos del Sitio Paso Otero 3: una aproximación al entendimiento de la organización de la tecnología lítica en el Curso Medio de Río Quequén Grande. Publicaciones de Arqueologia, 49: 3-22. CIFFyH-UNC.

MILLER, T. (1979): Stonework of the Xetá Indians of Brazil. Lithic Use Wear Studies. B. Hayden, Ed.: 401-408. Academic Press.

Moss, E. (1978): A variation of the method of microwear analysis developed by L. H. Keeley and its application to flint tools from Tell Abu Hureyra, Syria. Bulletin Institute of Archaeology, 15:238-239. University of London.

NANCE, J. (1971): Functional interpretation from microscopic analysis. American Antiquity, 36 (3): 361-366.

NELSON, M. (1991): The Study of Technological Organization. Archaeological Method and Theory, 3: $57-100$.

Plisson, J. (1985): Etude fonctionnelle d'outillages lithiques préhistoriques par lanalyse des micro-usures: recherche méthodologique et archéologique. Thése de Doctorat, Univ. de Paris 1. 357 p.

- (1986): Analyse des polis d'utilisation sur le quartzite. Technical Aspects of Microwear Studies on Stone Tools. Early Man News Parte 1, 47-50. Owen, L. y G. Unrath, Eds.

Politis, G. Y D. Olmo (1986): Preliminary Analysis of the Lithic Collecction of the La Moderna Site, Argentina. Current Research in Pleistocene Studies, Vol. 3: 36-38.

Politis, G. y M. A. Gutiéraez (1998): Gliptodontes y cazadores-recolectores de la Región Pampeana (Argentina). Latin American Antiquity, Vol. 9, Nro. 2: 111-134.

RatTo, N. (1991): Análisis funcional de las puntas de proyectil líticas de sitios del sudeste de la Isla Grande de Tierra del Fuego. Arqueologia, 1: 15t-178.

Ravn, M. (1993): Analogy in Danish Prehistoric Studies. Norway Archaelogical Review, Vol 26, Nro. 6: $59-90$.

SCHIFFER, M. (1972): Archaeological Context and Systemic Context. American Antiquity, 37 (2): $156-165$.

Semenov, S. (1964): Prehistoric Technology. Adams and Dart, Inglaterra. 211 p. - (1970): The forms and functions of the oldest tools. Quartar, 2: 1-20.

Trigger, B. (1992): Historia del pensamiento arqueológico. Crítica, Barcelona.

Unger-HAMILTON, R. (1984): The formation of use-weat polish on flint: Beyond the Deposit versus Abrasion Controversy. Journal of Archaeological Science, 11 (1): 91-98.

VAUGHAN, P. (1981): Lithic microwear experimentation and the functional analysis of a Lower Magdalenian stone tool assemblage. Tesis PH. D, Univ. of Pennsylvania. 618 p.

WILMSEN, E. (1968a): Functional analysis of flaked stone artifacts. American Antiquity, 33: 156161.

- (1968b): Lithic analysis in Paleoanthropology. Science, 161: 982-987.

WILMSEN, E. Y F. ROBERTS Jr.

- (1970): Lithic analysis and cultural inferences: A Paleoindian case. Anthropological Papers, University of Arizona 16. University of Arizona Press, Tucson.

WYLIE, A. (1982): An analogy by any other name is just as analogical: a commentary on the Gould-Watson dialogue. Journal of Anthropological Archaeology, 1: 382-401.

- (1985): The reaction against analogy. Advances in Archaeological Method and Theory, 8: 63-11. Schiffer, M. ed. Accademic Press, New York.

YaCOBACcio, H. (1991): Información Actual, Analogía e Interpretación del Registro Arqueológico. Actas del $X$ Congreso Nacional de Arqueologia Argentina. Shincal 3 (1): 185-194. San Fernando del Valle de Catamarca.

YOUNG, L. (1994): Lithics and adaptative diversity: an examination of limited-activity sites in Northeast Arizona. Journal of Anthropological Research, 50: 141-154. 